Gynäkologe $2013 \cdot 46: 607$

DOI 10.1007/s00129-013-3137-7

Online publiziert: 24. August 2013

(c) Springer-Verlag Berlin Heidelberg 2013

W. Distler ${ }^{1} \cdot$ M.W. Beckmann ${ }^{2}$

${ }^{1}$ Klinik und Poliklinik für Frauenheilkunde und Geburtshilfe, Universitätsklinikum Carl Gustav Carus Dresden

${ }^{2}$ Frauenklinik, Universität Erlangen

\title{
Fertilität und Krebs
}

das Netzwerk Ferti PROTEKT der Fertilitätsprotektion bei Chemo- und Strahlentherapie zu und zeigt mit interdisziplinärer wie interprofessioneller Aktivität, dass die Thematik wichtig ist und dass noch großer Nachholbedarf im Hinblick auf Information bezüglich der verschiedenen Verfahren der Fertilitätsprotektion und die Beratung sowie Betreuung der Betroffenen besteht [3].

\section{》) Zum Thema Fertilität nach Krebs besteht noch Nachholbedarf}

Wir hoffen, mit dem vorliegenden Themenheft umfassende Informationen zum Thema Fertilität und Krebs geben zu können. Die Herausgeber haben sich bemüht, das Spektrum der derzeitig vorhandenen Therapieoptionen einschließlich der technischen Aspekte umfassend darzustellen und einen Ausblick zu geben: sowohl zum "social freezing" wie auch zu ethischen Aspekten, die im Rahmen der Fertilitätsproduktion bedacht sein sollten.

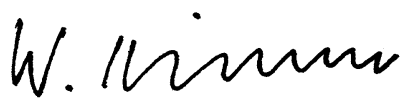

Prof. Dr. Wolfgang Distler

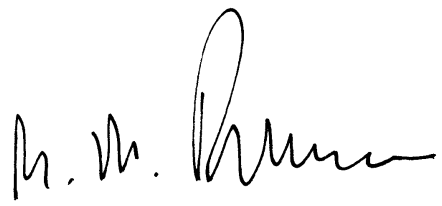

Prof. Dr. Matthias W. Beckmann

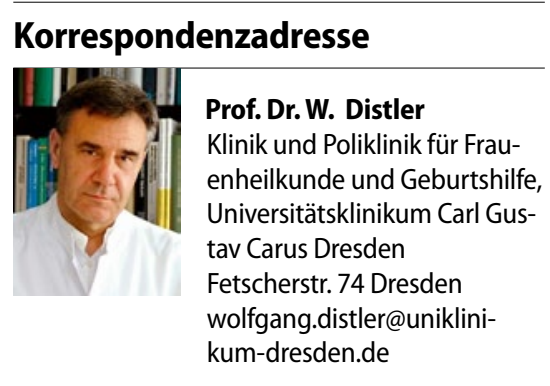

\section{Literatur}

1. Müller A et al (2012) Retransplantation von kryokonserviertem Ovarialgewebe: Erste Geburt in Deutschland. Dtsch Arztebl 109: 8-13

2. Dittrich R et al (2012) Live birth after ovarian tissue autotransplantation following overnight transportation before cryopreservation. Fertil Steril 97:387-390

3. www.fertiprotekt.de

4. Donnez J, Dolmans MM, Pellicer A et al. (2013) Restoration of ovarian activity and pregnancy after transplantation of cryopreserved ovarian tissue: a review of 60 cases of reimplantation. Fertil Steril 99(6):1503-1513 aufgrund einer Tumorerkrankung eine Strahlen- oder Chemotherapie erhalten müssen, macht sich Sorgen bezüglich einer späteren Beeinträchtigung ihrer Fertilität. Die Möglichkeit, nach überstandener Krebserkrankung eigene Kinder zu bekommen, ist mittlerweile ein wichtiger Bestandteil der erhofften späteren Lebensqualität dieser Frauen.

Die zunehmende Sensibilisierung für die Gesamtthematik durch Selbsthilfegruppen sowie ratsuchende Patientinnen und Patienten führte dazu, dass die Anstrengungen der Forschung auf diesem Gebiet deutlich größer geworden sind und sich auch entsprechende Erfolge nachweisen lassen. Seit 2006 wendet sich 